\title{
Graduate Students' Acceptance and Readiness for Open Distance Education in Kalinga State University
}

\author{
Jessie Grace M. Sannadan, Marilou B. Adora, Pinky Larcelle D. Lang-ay
}

Kalinga State University, Philippines

Received: 09 Oct 2020; Received in revised form: 13 Dec 2020; Accepted: 24 Dec 2020; Available online: 31 Dec 2020

(C)2020 The Author(s). Published by Infogain Publication. This is an open access article under the CC BY license

(https://creativecommons.org/licenses/by/4.0/).

\begin{abstract}
The study focuses on the graduate students' acceptability and readiness to Open Distance Education offered by Kalinga State University. The study found that the participants moderately accepted and is much familiar with the technologies commonly used in ODL. Also, it was found that there is a positive correlation between familiarity with technology and the acceptance of distance education and its constructs. However, the identified problems in offering ODL are much serious. Hence, if distance education is promoted, the University may need to improve students' perception of online education by educating them about its advantages, disadvantages, and requirements for success. Because the students currently hold that distance education does not improve one's reputation, it may be more useful to have campaigns with alumni or students that are known, respected, and successful. If an image is indeed one of the critical factors in the Kalinga culture, having testimonials from well-respected individuals may increase students' acceptance. Moreover, the University will need to invest in proper technological training and support, especially for online collaborative tools with which students are unfamiliar. The university has to equip computer labs with sufficient computers and reliable Internet for students who do not own computers at home.
\end{abstract}

Keywords—Open Distance Education, Graduate Students, Kalinga State University.

\section{INTRODUCTION}

In general, acceptance is defined as a "positive decision to use an innovation" (Simon, 2001). Decision-makers need to know the issues that influence users' decision to use a particular system so they would be able to take them into account during the development phase. It is the common question of both practitioners and researchers that why people accept new technologies. Answering this question may help them better design, evaluate, and predict the users' responses to new technologies (Mathieson, 2011).

Like several developing countries, e-learning and Information Communication Technology (ICT) have become a crucial part of a national effort to improve public education in the Philippines. More and more state universities are venturing into Distance E-learning or Distance Education.
Open and distance learning (ODL) is often used as a general term to cover educational approaches that reach students inconvenient or accessible places. It provides them with learning resources, or allow them to qualify in-person without attending school, or open up new opportunities to stay up-to-date regardless of where or when they want to study.

Distance Education (DE) is a learning experience commonly characterized by independent self-study with a time period to finish. Classes are online with specifically intended materials using electronic communication. There are also learning hubs for occasional class interaction and examinations.

Compared to its Asian neighbors, India, Pakistan, and Thailand, which began in the 1970s and 1980s, distance education in the Philippines is primary (Moore, 2005). 
Distance education is an organized, frequently accredited educational program where the learner is at a geographical and/or time distance from the provider of instruction, the educational institution, tutors, and where electronic or print media carry out all or much of the contact between teachers and students. The provider can attempt to use the two-way ability of, for example, mailed assignment markings, emails, mobile, tele-and video-conferencing, callin radio or $\mathrm{TV}$, as well as pre-recorded video or audio materials to resolve the physical distance and build in interaction. It can also add face-to-face components such as taking dispersed students to a study center or summer school for occasional tutored group meetings.

On the other hand, the central provider can send traveling tutors to the students or enter into contracts for locally-provided funding (e.g., by a formal or community school or university). An instance would be a program, presented by an open national university, providing preliminary teacher training at a distance to unqualified school-based teachers. The program permits the teacher to keep it up in situations and experiment with new practices in their direct classrooms.

The study determined the graduate students' acceptability and readiness to Open Distance Education offered by Kalinga State University, specifically the level of acceptability of the KSU graduate students to open Distance Education, the level of familiarity of graduate students with technologies commonly used in ODL and the degree of seriousness of problems/constraints identified in offering ODL in KSU.

\section{METHODOLOGY}

The study was conducted at Kalinga State University main campus, Bulanao, Tabuk City, Kalinga province. It utilized a mixed study design using both quantitative and qualitative techniques. Focus group discussions and interviews were conducted to gain more in-depth insight and validate the respondents' responses.

The study employed Moore and Benbasat's UTAUT models. The UTAUT structure builds on eight theoretical structures and tests the use of technology to predict technology use's purpose and actions. Performance expectation refers to the assumption of individuals that their performance will be improved by using the instrument. The expectation of effort is defined as the perception of the degree of ease when the tool is used.

The participants were graduate students of the Kalinga State University for the school year 2018 to 2019. The survey was distributed to 200 of the 470 graduate student population on campus. 147 questionnaires were returned. Surveys that were returned incomplete were discarded, leaving a total of 120 usable questionnaires, a $60 \%$ response rate.

A questionnaire was developed, which consisted of four major parts: (1) demographics, (2) acceptance of e-learning, and (3) familiarity with technology, (4) problems with distance education.

In part two, 25 items measure e-learning acceptance on a 5-point scale. Of these, 12 items were adapted from three constructs in the UTAUT(Unified Theory of Acceptance and Use of Technology) model: performance expectancy (4 items), effort expectancy (5 items), attitude toward e-learning ( 3 items),.Another 13 items were adapted from Moore and Benbasat's (1991) constructs of image and compatibility. The researchers selected and modified these items with close consultation with other professors at the campus.

Modified from Son, Robb, and Charismiadji (2011), the second set of queries asked the students to report about their use of technology in frequency (from "never" to "every day"). Text processing, spreadsheets, e-mail, search engines, Google Drive, discussion boards, text chat, voice chat, video chat, photo-based websites, video-based websites, wikis, blogs, sports, and social networking were included in the technologies. As they are mostly used for online learning, these technologies were chosen. The last set of questions determined the problems perceived by the respondents as problems in distance education.

The researchers sought permission from concerned authorities before the conduct of the study. After approval, the survey was administered to the graduate student-participants, and questionnaires were personally retrieved. Focus group discussions and interviews were also conducted to validate the responses from the survey questionnaire.

The data were analyzed thru the statistical software SPSS. To answer the research questions, descriptive statistics were calculated. To identify associations between variables and constructs, the Pearson correlation test was conducted. To explore and validate construct validity, factor analysis, and Cronbach's alpha reliability test were used. 


\section{RESULTS AND DISCUSSION}

Table 1. Acceptance of Open Distance Education among KSU Graduate Students

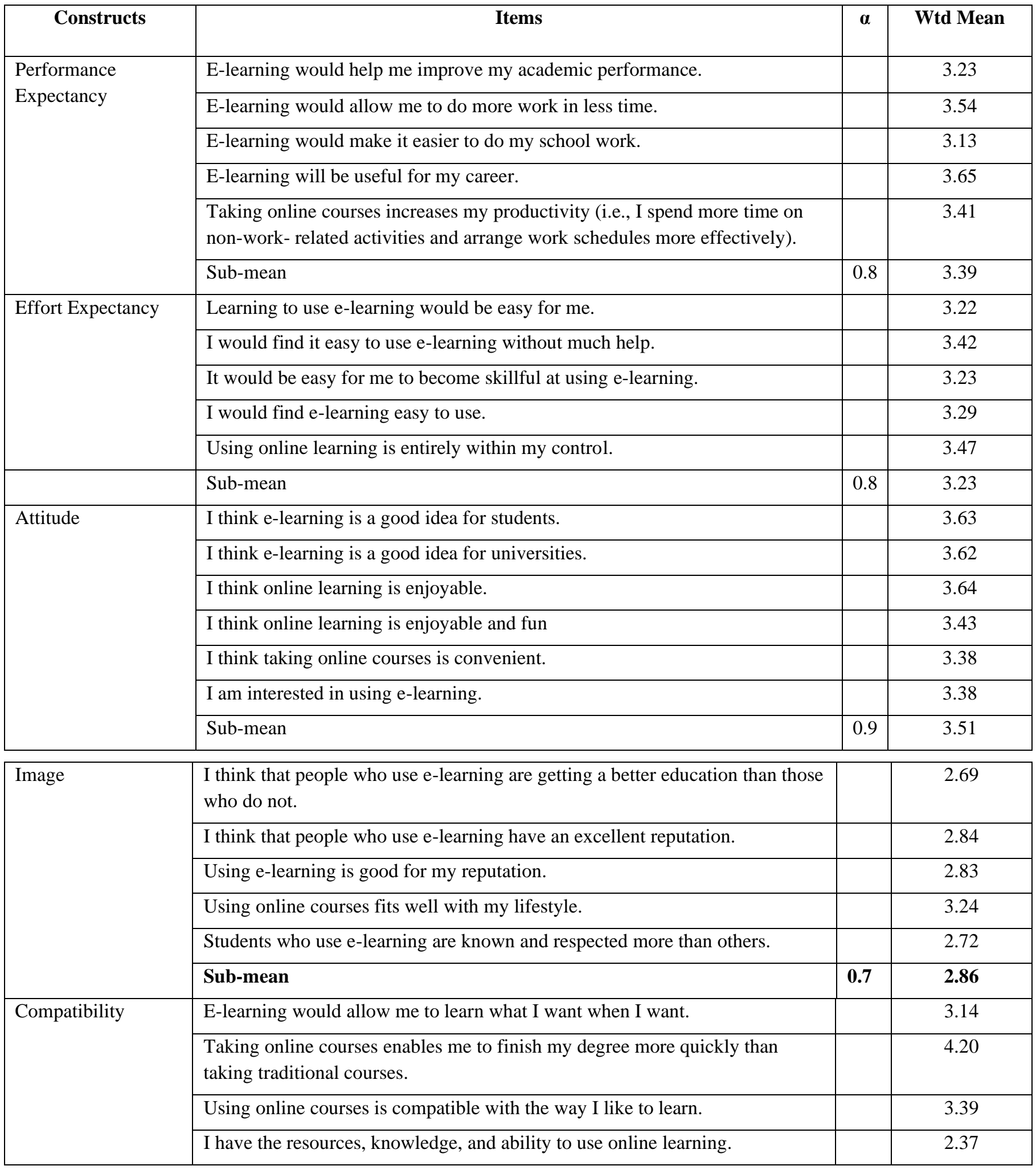




\begin{tabular}{|l|l|c|c|}
\hline & I feel that e-learning is at least equal quality to classroom learning. & 2.52 \\
\cline { 2 - 4 } & Sub-mean & $\mathbf{0 . 7 4}$ & $\mathbf{3 . 1 2}$ \\
\hline TAWM & & $\mathbf{3 . 2 2}$ \\
\hline
\end{tabular}

This study explored graduate students' level of acceptance for Distance Education. The participants indicate moderate acceptance of distance, as shown by the total average weighted mean of 3.22. It is conceivable that a lower acceptance among the graduate students is due to a lack of information leading to a lower knowledge of and experience with online education.

This study found that attitude has an internal consistency of .9, indicating a strong technology acceptance indicator. This can also be seen in the obtained sub-area mean of 3.51. In other words, students who believe distance learning is beneficial and easy to use appear to have positive attitudes towards distance learning as well.

Moderate levels of acceptance extend to performance expectancy, effort expectancy, image, and compatibility.

It is noteworthy that the lowest mean of 2.86 is along with the image construct. Therefore, it can be said that the respondents tend to believe that distance learning does not enhance the user's reputation. This must be addressed to raise the acceptance of the distance education program of the university. This is because image or reputation is an essential characteristic of Filipino culture in general and Kalinga culture. Enshrined in the Kalinga core value of Bain (Amistad, 2002), which deals with relationships with fellowmen, is the preservation of an individual's image and reputation. Hard work is the key to building and maintaining a reputation among Kalingas. The respondents claim that getting a degree without going to school is not hard work. The recurring comment was:

"Di pay naglaka to gayamen tmangpalpas ti masters ken doctorate."

- (Getting a master's and doctorate would be very easy)

With this statement, it is evident that the respondents do not consider getting an online degree as contributing positively to their image. It can also be said that the respondents belong to the many people who still think the quality of online courses is lower; that online courses aren't held to the same standards as traditional courses.
Besides, it is also a common misconception about online courses; students enroll in online courses thinking they'll get an easy (York, 2017).

Table 2. Familiarity with Technology

\begin{tabular}{|c|c|}
\hline Tools/Technology & Mean \\
\hline Word processing (e.g., MS Word) & 4.49 \\
\hline Spreadsheet (e.g., MS Excel) & 3.61 \\
\hline E-mail & 4.33 \\
\hline Search Engine (e.g., Google, Yahoo) & 4.75 \\
\hline Google Drive & 3.64 \\
\hline Text chat (e.g., LINE, Viber, Wechat, & 4.33 \\
\hline WhatsApp) & 3.32 \\
\hline Voice chat (e.g., Google Hangout) & 3.33 \\
\hline Video chat (e.g., Skype) & 3.59 \\
\hline Computer games & 4.49 \\
\hline Web Video (e.g., YouTube) & 4.37 \\
\hline Photo-focused web (e.g., Instagram) & 3.05 \\
\hline Blog (e.g., Blogger, Blogspot) & 3.45 \\
\hline Wikis (e.g., Wikipedia, Wikispace) & 4.78 \\
\hline Social Media (e.g., Facebook, Twitter) & 3.97 \\
\hline TAWM & \\
\hline
\end{tabular}

The study also shows that the students are much more familiar with technology than the total average weighted mean of 3.97. The respondents are very familiar with social media (Facebook, Instagram), search engines, web-video (e.g., YouTube), and text chat. They are less accustomed to tools such as wiki, video chat, and blogs. These results confirm most literature conducted in developed countries. Students may use simple software tools to use the Internet, mainly for web browsing purposes, communicating via chat or Facebook with friends, and watching YouTube videos.

This study further reveals that all respondents own smartphones and 80\% own notebook computers, with only $7 \%$ of students own a desktop computer. Moreover, the smartphone is the topmost device the students use to connect to the Internet. These statistics support 
prior knowledge that many graduate students do not have computers at home and can only use computers at their workplace. The findings also support us to realize the high ownership rate of mobile devices, even in the province's more rural areas.
Ownership of notebooks and laptops is high among graduate students who are teachers. The teacher-respondents stated that a laptop is essential in delivering instruction and, most notably, in the encoding of school reports using templates and formats from the Department of Education.

Table 3. Correlation of Acceptance Constructs

\begin{tabular}{|c|c|c|c|c|c|c|c|}
\hline & $\mathrm{PE}$ & EE & A & I & $\mathrm{C}$ & FT & $\mathrm{ADE}$ \\
\hline Performance Expectancy & 1.000 & & & & & & \\
\hline Effort Expectancy & $.78 * *$ & 1 & & & & & \\
\hline Attitude & $.69 * *$ & $.67^{* *}$ & 1 & & & & \\
\hline Image & $.76^{* *}$ & $.79^{* *}$ & $.74^{* *}$ & 1 & & & \\
\hline Compatibility & $.71 * *$ & $.71 * *$ & $.73 * *$ & $.83 * *$ & 1 & & \\
\hline Familiarity with Technology & $.63 * *$ & $.62 * *$ & $.61 * *$ & $.62 * *$ & $.60 * *$ & 1 & \\
\hline Acceptance of Distance Education & $.84 * *$ & $0.90 * *$ & $0.86 * *$ & $0.53 * *$ & $.78 * *$ & $0.79 * *$ & 1 \\
\hline
\end{tabular}

This study also shows a positive relationship between familiarity with technology and the acceptance of distance education and its constructs. As a result, it is concluded that the students' decision to adopt distance education is contingent upon how accustomed they are to technology. In other words, students who are highly familiar with several types of technology have a positive perception of distance education.

This existing study found that performance expectancy and effort expectancy has a strong positive relationship and strong technology acceptance indicators. The image also appeared to have a positive relationship to acceptance at .53 , where the image is operationalized as reputation. This is remarkable since the interview result revealed that respondents do not consider getting an online degree as contributing positively to their image.

All of the factor results of this research model's items are higher than 0.50; most of them are above 0.70. Every item is loaded significantly ( $p<.01$ in all cases) on its constructs. All six constructs correlated highly with the general acceptance of e-learning.

Table 4. Problems in an Open Distance Education

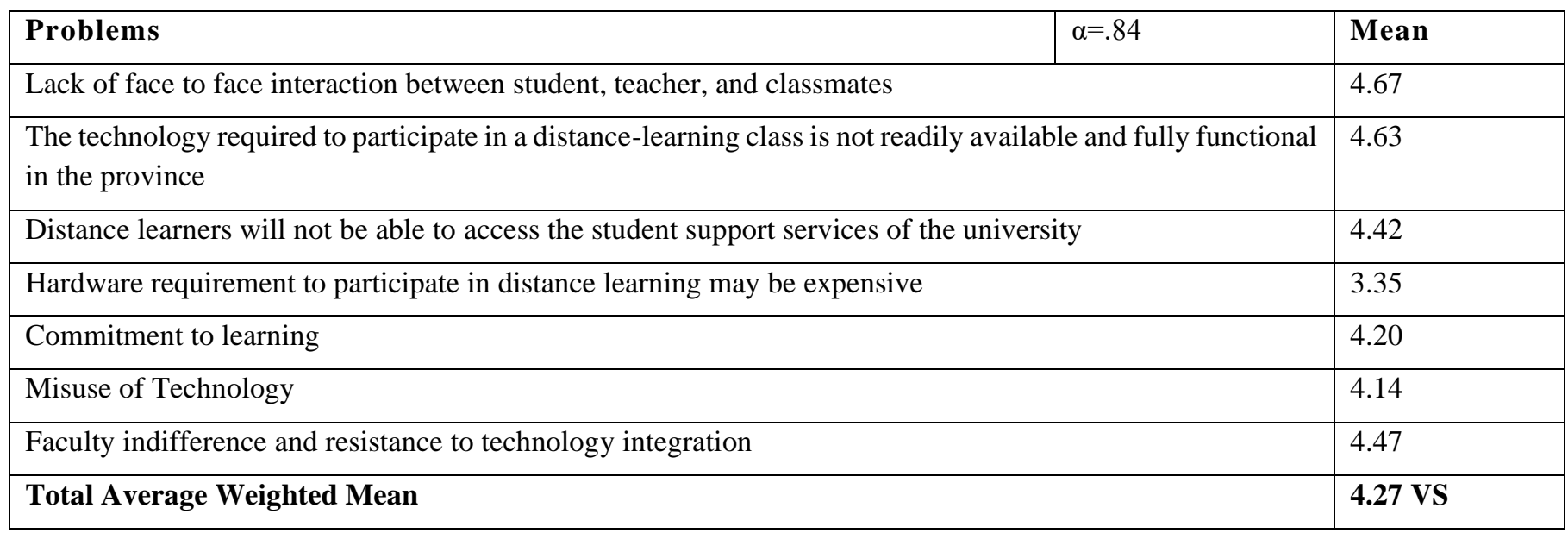


The study shows that the identified problems are much serious, as indicated by the total average weighted mean of 4.27 , with an alpha of .84 , indicating that the problems are valid and consistent, therefore must be addressed by the Kalinga State University.

Of the seven problems, only the Hardware requirement to participate in distance learning may be expensive is considered moderately serious. Two problems are deemed much serious. In contrast, the rest of the problems are described as very much serious.

Lack of face-to-face interaction between students, teachers, and classmates obtained the highest mean of 4.67 and, therefore, considered very serious by the respondents.

Distance learning implies a physical separation between the student and the teacher by its very meaning. For students who may need or want academic or technological help, this poses a challenge, and it can quickly become a source of frustration. Multiple communication methods, including a phone number and/or email address, along with general availability and response times, will be given by an efficient distance-learning teacher. Occasionally a "Help" discussion thread is involved in an asynchronous environment to allow peers to help each other. Interactive tools, such as discussion boards, wikis and blogs, and synchronous audio or video components. A sense of interaction and teamwork may further encourage community or paired projects. Students can feel alienated and become discouraged by a lack of meaningful interactivity. However, even with these support systems in place, the absence of regular office hours would cause students new to distance learning to adapt (Adams, 2016).

Another very serious problem facing distance education students is "the technology required to participate in a distance-learning class is not readily available and fully functional in the province." The equipment needed to take part in a distance learning class must be readily accessible and fully functional. Besides, to succeed in the course, students must have or obtain a certain degree of technical competency, including hardware, software, and related accessories. For distance learning students, a technology that is inaccessible or unreliable, quickly becomes an obstacle. There is an enormously challenging technology that is difficult to understand or use. For distance learning students, tutorials, user guides and other support structures should be in place to reduce - if not eliminate - this problem. As one respondent mentioned:

"Umay kamin to met lang ditoy Tabuk gapu ti signal, di ag-enrol kami lattan diay regular class."

(We still have to come to Tabuk to get an excellent signal to enroll in a regular class.)

Students must be committed to their performance in a distance-learning class. There is a certain degree of social pressure in a typical classroom environment: the teacher and other classmates expect each student to come to class every week, complete assignments, answer the teacher's questions, and participate actively in group projects. These habits are often anticipated in a distance-learning class, but the social pressure to comply is absent. Students need to have or learn to build the self-discipline needed to effectively organize their time and actively engage in the learning process. It can be a struggle to remain motivated when participating in online classes. Students can be pushed beyond their zones of comfort. For individual students, obstacles such as procrastination, feelings of loneliness, and lack of encouragement render enrolling online a significant change. Furthermore, some learners find an insufficient degree of technological expertise to exacerbate problems further.

Often, online learners feel lonely because they are unaware of the programs and resources available to them. Some students feel like they are not related and cannot access valuable information because online classes are not held on campus. Online students appear to feel isolated because there are no interactions with individuals face-to-face. Students are forced to be proactive about reaching out to each other by using the online chat options or forming online student groups or class Facebook pages. Likewise, they have to seek out institutional resources, such as the health center, tutoring labs, and the library. Institutional support to distance-learning students is a requirement for all colleges and universities offering distance education. Nevertheless, online students need to know that these services are available.

To complete assignments, online learners are expected to maintain an up-to-date computer and other technology resources. Students should also have a basic technical competence level and feel secure surfing the Internet and using email and chat services. Without a basic technological ability, many students enter online classes, which put them at a disadvantage. Students had to provide 
further instructions on taking full advantage of the presentation (Teaster \& Blieszer, 1999).

There is the risk, in addition to the expense of the technology, of not using all its capacity. Some of these problems derive from a lack of instruction, others from the teacher's attitudes about using the program, and others from hardware issues. The idea that tutors need to be qualified to use distance education technology seems to be self-evident, but too often, they are not. Once again, it seems that management can believe that the program itself will enhance the path. Technological progress does not contribute to productive distance education. The best practices in distance education rely on innovative, well-informed tutors (Greenberg, 1998); Bates (1995) show that modern technologies are not necessarily better than old ones. Many of the lessons learned from the use of older technologies are also applicable to every new technology. Again, the mentor should be qualified to benefit from their expertise and adapt the experience to the current distance learning environment. "Because teaching a distance education class includes a new role for tutors, then administrators must provide the time, the tools, and the training to meet these new responsibilities" (Inmam \& Kerwin, 1999). The teachers must be prepared "not only to use technology but also to improve the way material is organized and distributed" (Palloff \& Pratt, 2000).

Indeed, changing teachers' pedagogical orientations and approaches require a broadening of the teachers' awareness of the pedagogic opportunities afforded by learning technologies and the development of their knowledge and skills in online learning design through a professional development program that fosters critical reflection on technology use in teaching and learning (Hughes, 2004; Daly \& Pachler, 2007).

\section{LIMITATIONS AND FUTURE RESEARCH}

This study had several limits that could be addressed in future studies. First, the results were based on graduate students. They could benefit from comparison with results obtained from the same model aimed at students from a wider variety of educational levels (e.g., undergraduate, senior, and high school students). Second, this study was cross-sectional and conducted within a short period. Students' perceptions of effort expectancy, performance expectancy, image, compatibility, and familiarity with technology toward distance education can change over time as new knowledge and experiences are accumulated. Thus, future studies could employ a longitudinal design to obtain more accurate findings from a specific group. Finally, other variables such as system quality, trust, and mobile information literacy may also moderate the relationship between acceptance and variables. Therefore, these variables should be considered as moderators in future studies. Finally, this study used a self-reported questionnaire as the research tool. In a questionnaire, interviewees might not express their genuine opinions when answering questions, leading to errors in the results. This problem should be handled cautiously when interpreting research data.

\section{SUMMARY}

The study found that the participants moderately accepted and are much familiar with the technologies commonly used in ODL. Also, it was found that there is a positive correlation between familiarity with technology and the acceptance of distance education and its constructs. However, the identified problems in offering ODL are much serious.

\section{CONCLUSIONS}

This study's results provide a few practical implications to Kalinga State University in its plan to offer distance education. In general, KSU's leaders need to recognize the need for strategic policy development and organizational restructuring for distance education to be effectively implemented. Collis \& van der Wende (2002) noted that "Policies are crucial for institutions to define what will be their next stage of development and how to get there" (p. 66). Arinto (2016) also recommend in particular that a university intending to implement e-learning "should develop a strategic plan relating to the relative importance to the institution of different types of learners" and "profile itself around several instructional alternatives and develop pedagogical models and templates for its course management system that support those models" with an eye towards "efficiencies and scalability" (Collis \& van der Wende, 2002 p. 72). Which pedagogical profiles in distance education should KSU explore, and how should it "optimize flexible delivery of these profiles" (Collis \& van der Wende, p. 72) The following questions, which are adapted from Bates (2000), may be used as a guide in the strategic planning required for these more significant questions to be addressed: 
1. On which target group(s) should KSU be focused (e.g., high school graduates, working adults, lifelong learners, overseas Filipino workers)?

2. How should the blended approaches vary, depending on the target group?

3. For which teaching and learning goals should asynchronous and synchronous strategies be used?

4. Which particular technologies are needed?

5. How should faculty be supported?

Finally, Distance learning offers vast potential for students who want to take a class but are physically incapable of attending a regular classroom. It offers flexibility that many students find appealing; still, others find this flexibility challenging, daunting, or frustrating. Distance-learning classes can present difficulties for students in support, interactivity, commitment, and technology. Kalinga State University must find solutions to these problems to develop its distance education program effectively.

\section{RECOMMENDATIONS}

1. The University may need to improve students' perception of online education by educating them about its advantages, disadvantages, and requirements for success. Because the students currently hold that distance education does not improve one's reputation, it may be more useful to have campaigns with alumni or students that are known, respected, and successful. If an image is undoubtedly one of the critical factors in the Kalinga culture, having testimonials from wellrespected individuals may increase students' acceptance.

2. The University will need to invest in proper technological training and support, especially for online collaborative tools with which students are unfamiliar.

3. The university has to prepare computer labs with adequate computers and reliable Internet for students who do not have computers at home. Likewise, because most students own mobile devices, the e-learning platform may require mobile-friendly to accommodate students who may access online lessons using their smartphones.

\section{REFERENCES}

[1] Adams, Jonathan \& Ngampornchai, Anchalee (2016), International Journal of Educational Technology in Higher Education volume 13, Article number: 34

[2] Adams, J. (2008). Understanding the factors that limit the acceptability of online courses and degrees. International Journal on E-Learning.

[3] Addah, J. (2012). Computer literacy and E-learning: Attitudes among first-year students in a Ghanaian medical school. International Journal of Computer Applications, 51, 22.

[4] Akhu-Zaheya, L. M., Khater, W., Nasar, M., \& Khraisat, O. (2011). Baccalaureate nursing students' anxiety-related computer literacy: a sample from Jordan. Journal of Research in Nursing, 18(1), 36-48.

[5] Alip, A. et al. (2004). UPOU online and face-to-face students' perspectives on support services needs. UPOU Research Monograph Series Vol. 1.

[6] Alviar-Escobin, A. (2004). User perceptions of internet technology in distance education. UPOU Research Monograph Series Vol. 1.

[7] Annual Report, 1996. (, 1997). University of the Philippines Open University.

[8] Annual Report, 1997. (, 1998). University of the Philippines Open University.

[9] Annual Report, 1998. (, 1999). University of the Philippines Open University.

[10] Annual Report, 2000. (, 2001). University of the Philippines Open University.

[11] Annual Report 2001-2007. (, 2007). University of the Philippines Open University.

[12] Annual Report 2007-2009. (, 2010). University of the Philippines Open University.

[13] Arinto, Patricia (2016) Issues and Challenges in Open and Distance e-Learning: Perspectives from the Philippines International Review of Research in Open and Distributed Learning Volume 17, Number 2

[14] Bates, T. (2000) Distance education in dual-mode higher education institutions: Challenges and changes. http://bates.cstudies.ubc.ca/papers/challengesandchanges.html Ferguson, L., \&

[15] Bhuasiri, W., Xaymoungkhoun, O., Zo, H., Rho, J. J., \& Ciganek, A. P. (2012). Critical success factors for e-learning in developing countries: A comparative analysis between ICT experts and faculty. Computers \& Education, 58, 843-855.

[16] Bediang, G., Stoll, B., Geissbuhler, A., Klohn, A., Stuckelberger, A., Nko'o, S., \& Chastonay, P. (2013). Computer literacy and E-learning perception in Cameroon: the case of Yaounde Faculty of Medicine and Biomedical Sciences. BMC Medical Education, 13, 57.

[17] Bill to institutionalize distance education under study. Committee News. Philippines Congress: House of Representatives in the Philippines. Retrieved May 12, 2010, 
from http://congress.gov.ph/committees/commne ws/commnews_det.php?newsid=915

[18] Brinkerhoff, R., et. al. (1983). Program evaluation. Boston: Kluwer-Nijhoff Publishing. Distance Education. (, 1987). Proceedings of the Regional Seminar on

[19] Carsten, P., \& Temphairojana, P. (2013). Thailand's boom: To the northeast, the spoils. Reuters Business News, Downloaded May 22, 2015, from http://www.reuters.com/article/2013/06/16/us-thailandnortheast-idUSBRE95F00H20130616.

[20] Collis, B. \& van der Wende, M. (2002). Models of technology and change in higher education. An international comparative survey on the current and future use of ICT in Higher Education. Enschede, Netherlands: University of Twente.

[21] Davis, F. D., Bagozzi, R. P., \& Warshaw, P. R. (1989). User acceptance of computer technology: A comparison of two theoretical models. Management Science, 35(8), 982-1003.

[22] Decade 2020. (, 2015). Social Justice Part 1: Problems and Solutions in Thailand. Retrieved from http://decade2020.com/problems-and-solutions-inthailand.

[23] Distance Education. Bangkok, Thailand. Evaluation in distance education. (, 2004). UPOU Research Monograph Series, Volume 2.

[24] Evans, T. (1994). Understanding learners in open and distance education. London: Kogan Page.

[25] Foley, J. A. (2005). English in...Thailand. Regional Language Centre Journal, 36(2), 223-234.

[26] Folorunso, O., Ogunseye, O. S., \& Sharma, S. K. (2006). An exploratory study of the critical factors affecting the acceptability of e-learning in Nigerian universities. Information Management \& Computer Security, 14(5), 496-505.

[27] Johri, P. (2005). Modern distance education. India: Anmol.

[28] Ikpe, I. B. (2011). E-learning platforms and humanities education: An African Case Study. International Journal of Humanities and Arts Computing, 5(1), 83-101.

[29] Im, I., Hong, S., \& Kang, M. S. (2011). An international comparison of technology adoption Testing the UTAUT model. Information \& Management, 48, 1-8.

[30] Inman, E., \& Kerwin, M. (1999). Instructor and student attitudes toward distance education. Community College Journal of Research \& Practice, 23 (6), 581-592.

[31] Iqbal, M. J., \& Ahmad, M. (2010). Enhancing quality of education through e-learning: The case study of Allama Iqbal Open University. Turkish Online Journal of Distance Education, 11, 84-97.

[32] Keegan, D. (Ed.) (1993). Theoretical principles of distance education. London :

[33] Routledge. Librero, F. (n.d.). Early years of distance education at the University of the Philippines. Retrieved April 12, 2011, from $\quad$ http://www.upou.edu.ph/papers/flibrero_20 09/earlyyearsofDE.pdf
[34] Khaopa, Wannapa. (2012, November 26). Thailand could be a significant e-learning hub in the region. The Nation. Retrieved from http://www.nationmultimedia.com/national/Thailandcould-be-major-e-learning-hub-in-region-30195003.html.

[35] Kijsanayotina, B., Pannarunothaib, S., \& Speedie, S. M. (2009). Factors influencing health information technology adoption in Thailand's community health centers: Applying the UTAUT model. International Journal of Medical Informatics, 7(8), 404-416.

[36] Lee, Y.-H., Hsieh, Y.-C., \& Hsu, C.-N. (2011). Adding Innovation Diffusion Theory to the Technology Acceptance Model: Supporting Employees' Intentions to use E-Learning Systems. Educational Technology \& Society, 14(4), 124-137.

[37] Librero, F. (2005). Some external factors of learning in a knowledge-based society. $19^{\text {th }}$ Annual Conference of the Asian Association of Open Universities, Jakarta, Indonesia. Retrieved October 20, 2010, from http://www.idrc.ca/uploads/user-

[38] S/11285250761F_Librero_PLENARY_PAPER_10805.pdf

[39] Lontoc, J. (2010). UPOU expands public enrollment of paying students. UP Newsletter Vol. xxxi Issue 03. Retrieved October 12, 2010, from http://www.up.edu.ph/upnewsletter.php?i=1 $60 \&$ archive $=$ yes $\&$ yr $=2005 \& m n=10$

[40] Madaus, G., Scriven, M., \& Stufflebeam, D. (Eds.) (1986). Evaluation models : Viewpoints on educational and human services evaluation. Boston: Kluwer- Nijhoff Publishing.

[41] Mathieson, K (1991) Predicting user intentions: comparing the technology acceptance model with planned behavior theory. Information Systems Research. 2(3) (1991) 173-191.

[42] Moore, G. C., \& Benbasat, I. (1991). Development of an instrument to measure the perceptions of adopting an information technology innovation. Information Systems Research, 2, 192-222.

[43] Moore, M., \& Kearsley, G. (2005). Distance education: A systems view. Wadsworth.

[44] Moran, L., \& Mugridge, I. (Eds.) (1993). Collaboration in distance education : International case studies. London: Routledge.

[45] Oliver, M. (2014). Online learning helps prepare pupils for university. Education Journal, 218, 12-15.

[46] Pagram, P., \& Pagram, J. (2006). Issues in e-learning: A Thai case study. The Electronic Journal of Information Systems in Developing Countries, 26(6), 1-8.

[47] Pardamean, B., \& Susanto, M. (2012). Assessing User Acceptance toward Blog Technology Using the UTAUT Model. International Journal Of Mathematics And Computers In Simulation, 6(1), 203-212.

[48] Palloff, R., \& Pratt, K. (2000). Making the transition: Helping teachers to teach online. Paper presented at EDUCAUSE: Thinking it through. Nashville, Tennessee. (ERIC Document Reproduction Service No. ED 452 806).

[49] Park, S. Y. (2009). An analysis of the Technology Acceptance Model in understanding university students' behavioral 
intention to use e-learning. Educational Technology \& Society, 12(3), 150-162.

[50] Pintrich, P. R. (2000). The role of goal orientation in selfregulated learning. In M. Beokaerts, P. R. Pintrich, \& M. Zeidner (Eds.), Handbook of self-regulation (pp. 452-502). New York: Academic.

[51] Quimbo, M.A.T. (2002). A model for evaluating distance education program. In H.P. Dikshit, S. Garg, S. Panda, \& Vijayshri (Eds.), Access \& Equity: Challenges for open and distance learning, (pp. 196-213). New Delhi: Kogan Page.

[52] Rashid, Nadia \& Rashid, Muhammad (2012) Issues and Problems in Distance Education. Turkish Online Journal of Distance Education-TOJDE January 2012 ISSN 1302-6488 Volume: 13 Number: 1

[53] Readiness towards distance learning (2004). UPOU Research Monograph Series, Volume 1.

[54] Rogers, E. M. (1983). Diffusion of Innovations (3rd ed.). New York: Free Press.

[55] Rueangprathum, A., Philuek, W., \& Fung, C. C. (2009). Elearning in Thailand $-A$ survey of the current situation and trend. Paper presented at the International Conference on Teacher Professional Development: Searching for New Paradigms, Agendas, and Networks (ICONTPD 2009).

[56] Saekow, A., \& Samson, D. (2011). E-learning readiness of Thailand's universities comparing to the USA's cases. International Journal of e-Education, e-Business, $e$ Management, and e-Learning, 1(2).

[57] Saengpassa, Chularat. (2013, December 2). E-learning slow to progress in Thailand. The Nation. Retrieved

[58] from http://www.nationmultimedia.com/national/E-Learningslow-to-progress-in-Thailand-30221101.html.

[59] Saowapon, C., Laohajaratsaeng, T., Thammajinda, R., \& Singharajwarapan, S. (2001). Education reform and e-learning in Thailand. Retrieved from http://www.oecd.org/education/skills-beyondschool/2428376.pdf.

[60] Sherritt, C. (1996). A fundamental problem with distance programs in higher education. (Opinion paper, no.120). viewpoints. (ERIC Document Reproduction Service No. ED389 906)

[61] Simon, B. Wissensmedien im Bildungssektor. Eine Akzeptanzuntersuchung an Hochschulen (Knowledge media in the education system: acceptance research in universities), WU Vienna University of Economics and Business: Wien, Austria, 2001, p. 179.

[62] Simonson, M. et al. (2006). Teaching and learning at a distance: Foundations of distance education. London: Pearson.

[63] Siritongthaworn, S., Krairit, D., Dimmitt, N. J., \& Paul, H. (2006). The study of e-learning technology implementation: A preliminary investigation of universities in Thailand. Education and Information Technologies, 11(2), 137-160. http://dx.doi.org/10.1007/s11134-006-7363-8.
[64] Son, J., Robb, T., \& Charismiadji, I. (2011). Computer literacy and competency: A survey of Indonesian teachers of English as a foreign language. CALL-EJ, 12(1), 26-42.

[65] Teaster, P. \& Blieszner, R. (1999). Promises and pitfalls of the interactive television approach to teaching adult development and aging. Educational Gerontology, 25 (8), 741-754.

[66] Teo, T., Luan, W. S., Thammetar, T., \& Chattiwat, W. (2011). Assessing e-learning acceptance by university students in Thailand. Australasian Journal of Educational Technology, 27(Special issue, 8), 1356-1368.

[67] Trinidad, A. (2004). Technological and educational preparedness of the Philippines for e-learning: A review of available literature. UPOU Research Monograph Series, Vol. 1.

[68] Thomas, Marcie. (2019, August 31). The Problems Faced by Students in Distance Learning. classroom.synonym.com. Retrieved from https://classroom.synonym.com/problemsfaced-students-distance-learning-1303.html

[69] Vate-U-Lan, P. (2007). The readiness of eLearning Connectivity in Thailand(Conference paper presented at the Fourth International Conference on eLearning for Knowledge-based

[70] Venkatesh, V., Morris, M. G., Davis, G. B., \& Davis, F. D. (2003). User acceptance of information technology: Toward a unified view. MIS Quarterly, 27, 425-478.

[71] Wijekumar, K. (2000). Effective design and use of web-based distance education environments. Professional Safety, 45 (12), 28-33 Greenberg, G. (1998). Distance education technologies: Best practices for K-12 settings. IEEE Technology and Society Magazine (Winter) 36-40. 